http://dx.doi.org/10.18232/alhe.1019

Artículos

\title{
La diversificación del grupo empresarial Macri en el sector automotriz durante la última dictadura militar en Argentina
}

\section{The Diversification of the Macri Business Group in the Automotive Sector during the Last Military Dictatorship in Argentina}

\author{
Alejandro Gaggero ${ }^{1,2, *}$ (D) 0000-0003-4488-4285 \\ Bruno Perez-Almansi ${ }^{1,2}$ iD 0000-0003-2142-7241 \\ ${ }^{1}$ Consejo Nacional de Investigaciones Científicas y Técnicas, Buenos Aires, Argentina. \\ ${ }^{2}$ Universidad Nacional de San Martín, Provincia de Buenos Aires, Argentina \\ *Correspondencia: agagge@yahoo.com
}

Resumen. El objetivo de este artículo es analizar la diversificación del grupo empresarial Macri entre fines de la década 1970 y principios de la de 1980, enfocándose en un hito central en la historia de la organización: su desembarco en la producción automotriz a través de la adquisición de la automotriz Sevel, fabricante de Fiat y Peugeot. La estrategia exitosa de este grupo fue posible debido a tres procesos que se dieron en aquellos años: la reestructuración que estaba desarrollando Fiat a nivel global, la reconversión de la producción automotriz argentina a partir del giro en la política económica que se produjo durante la dictadura militar, y la expansión que había experimentado Macri en la industria de la construcción en el periodo previo a la adquisición. Se utilizan como fuente principal entrevistas a exgerentes, artículos de revistas empresariales y estadísticas sectoriales.

CÓMO CITAR: Gaggero, A y Pérez-Almansi, B. (2020). La diversificación del grupo empresarial Macri en el sector automotriz durante la última dictadura militar en Argentina. América Latina en la Historia Económica, 27(2), e1019. DOI:10.18232/alhe.1019 
Palabras clave: empresas nacionales; empresas transnacionales; industria automotriz.

Abstract. The objective of the article is to analyze the diversification of the Macri business group between the end of the 70's and the beginning of the 80 's, focusing on a central milestone in the history of the organization: its arrival in the automotive production through the acquisition of the Sevel automaker, manufacturer of Fiat and Peugeot. The successful strategy of the group was possible due to three processes that occurred in those years: the restructuring that Fiat was developing globally, the reconversion of the Argentine automotive production from the turn in the economic policy that took place during the military dictatorship and the expansion that Macri had experienced in the construction industry in the period prior to the acquisition. The article uses interviews with former managers, articles from business journals and sector statistics as main sources.

Key words: national companies; transnational companies; automotive industry.

JEL: L62; N66; N76.

Recibido: 27 de agosto de 2018

Aceptado: 25 de febrero de 2019

Publicado: 10 de febrero de 2020

Organismo patrocinador: Instituto de Altos Estudios Sociales, Universidad Nacional de San Martín

Agradecimiento: Una versión previa a este trabajo se presentó en las VI Jornadas de Historia de la Industria y los Servcios, organizadas por el Área de Estudios Sobre la Industria Argentina y Latinoamericana de la Universidad de Buenos Aires. Agradecemos los comentarios y sugerencias de Norma Lanciotti, Ana Castellani y los dos evaluadores de la revista.

\section{INTRODUCCIÓN}

Existe una abundante bibliografía que analiza la expansión de un conjunto de grupos económicos de origen argentino durante las décadas de 1970 y 1980, en el marco de un fuerte estancamiento de la economía y crisis recurrentes en Argentina. Este fenómeno estuvo asociado, en gran medida, a la dinámica macroeconómica e institucional resultante de los cambios estructurales forjados por la última dictadura militar. La clave para crecer en un contexto aparentemente adverso fue la capacidad de estos grupos empresariales para aprovechar las oportunidades asociadas a la inestabilidad política y económica que caracterizó a esta etapa (Azpiazu y Basualdo, 1989; Barbero y Lluch, 2016; Schvarzer, 1983 y 1994) 1 $^{1}$

La bibliografía disponible señala que un elemento central en esta expansión fue la instauración de estrategias orientadas a sacar provecho de las diferentes políticas de incentivos que el Estado dirigía al sector privado, las cuales respondían a un cambio dado a partir de mediados de la década de 1960 por las elites políticas -civiles y militares- que fomentaron en mayor medida el crecimiento del capital nacional concentrado, al que veían como un socio necesario para el desarrollo de Argentina. Este factor se sumó a la baja autonomía relativa del Estado y al poder político que alcanzaron los empresarios nacionales, lo cual les permitió lograr la continuidad de las medidas de promoción incluso en etapas críticas para la economía argentina.

\footnotetext{
${ }^{1}$ La reestructuración de la cúpula empresarial a partir de la década de 1970 implicó que una parte de los grupos económicos más importantes hasta ese momento perdieran posiciones o incluso desaparecieran, como en los casos de Sasetru y Grecco. Véanse Basualdo (2006) y Schvarzer (1983).
} 
El contexto institucional que caracterizó a este periodo hizo que las relaciones políticas entre los empresarios y los diferentes elencos gubernamentales se transformaran en un activo clave para los propietarios de los grupos económicos. Los beneficios derivados del apoyo estatal y la protección comercial les permitieron compensar las consecuencias negativas de la inestabilidad y el estancamiento macroeconómico (Azpiazu y Basualdo, 1989; Castellani, 2009). Esta dinámica se produjo principalmente en sectores que habían sido elegidos por el sector público como polos de desarrollo o en aquellos en los cuales las empresas estatales tenían un fuerte protagonismo. La mayor parte de los grupos que logró consolidarse en este contexto fue de tipo diversificado y con control o de gestión familiar (Barbero y Lluch, 2016).

No obstante, gran parte de la producción académica sobre el tema se basa en el análisis de las transformaciones ocurridas al nivel de la cúpula empresarial de Argentina -las 200 firmas de mayores ventas-, pero son relativamente escasos los estudios sobre las estrategias de grupos económicos específicos durante las décadas de 1970 y 19802 Pero, durante los últimos años, han aparecido distintas investigaciones enfocadas a sectores puntuales y las firmas que los lideraban. De esta producción destaca Iramain (2013), que muestra que la reestructuración de la siderurgia durante la última dictadura militar generó fuertes beneficios para los dos principales grupos económicos nacionales (Techint y Acindar), en contraste con el deterioro que experimentó gran parte de las pequeñas y medianas empresas del sector. Este desempeño se logró, en buena medida, gracias a la intervención estatal; por ejemplo a través de la política de promoción industrial, que permitió a los conglomerados más importantes integrarse verticalmente y aumentar su escala productiva. Castellani y Serrani (2010) y Barrera (2012), por su parte, destacan la importancia que tuvo el sector público en la expansión de los grupos empresariales petroleros, gracias a la privatizción periférica de Yacimientos Petrolíferos Fiscales. En este caso, fue la tercerización de actividades que hasta ese momento realizaba la empresa estatal lo que permitió el rápido crecimiento del capital concentrado local.

No existen investigaciones académicas que se enfoquen específicamente sobre la estrategia del grupo empresarial Macri durante la última dictadura cívico-militar, a pesar de su notable expansión y protagonismo -tanto económico como político- que adquirió durante la transición democrática ${ }^{3}$ Sin embargo, su trayectoria muestra una particularidad en relación con los casos mencionados en los párrafos anteriores, ya que el principal hito de su crecimiento fue el desembarco en la producción automotriz, un sector afectado por las políticas de apertura.

Este artículo expone los primeros resultados de una investigación sobre la expansión del grupo empresarial Macri entre finales de la década de 1970 y principios de la de 1980. El eje está puesto en el desembarco de la producción automotriz a través de la adquisición de Sevel, firma que producía los vehículos de las marcas Fiat y Peugeot. Esta operación constituyó un punto clave en la historia del grupo que transformó a su propietario en uno de los principales industriales del

\footnotetext{
${ }^{2}$ Entre los estudios, véanse Schvarzer (1994) y Green y Laurent (1988) sobre el grupo Bunge y Born; Rougier (2012) sobre el grupo Madanes, y Castro (2014) sobre la principal firma del grupo Techint.

${ }^{3} \mathrm{El}$ crecimiento del grupo Macri durante la última dictadura militar fue sustancial, ya que pasó de ser una organización anclada en la construcción sin presencia entre las 200 empresas de mayores ventas en el país, a transformarse en un grupo diversificado con liderazgo en sectores clave de la industria y los servicios. De hecho, el grupo aparece como uno de los protagonistas del nuevo poder económico de Argentina durante la transición democrática (Azpiazu, Basualdo y Khavisse, 1989). A pesar de su importancia, no existen investigaciones académicas centradas en la historia de su expansión. El conocimiento sobre este tema puede rastrearse parcialmente en trabajos sobre los sectores en los cuales Socma, la empresa holding del grupo, tuvo presencia (como la construcción, los servicios urbanos y la industria automotriz).
} 
país durante la década de 1980 4 La operación reviste un interés especial; en primer lugar, porque formó parte de un proceso más amplio: la retirada de Argentina de una parte de las principales empresas automotrices transnacionales entre fines de la década de 1970 y principios de la de 1980. Mientras que en algunos casos la falta de inversión implicó el cierre de las fábricas (General Motors); en otros (Fiat, Peugeot y Citröen), la producción fue transferida a grupos locales que hasta ese momento ocupaban posiciones secundarias en la elite empresaria local $5^{5}$ No ocurrió lo mismo en Brasil y México -los otros dos fabricantes líderes de automóviles en la región-, donde las multinacionales mantuvieron o incrementaron su presencia ${ }^{6}$

El grupo Macri fue el ejemplo más claro de una trayectoria exitosa en esta reestructuración sectorial. A inicios de la década de 1970 la organización estaba enfocada en el sector de la construcción mediante siete empresas, de las cuales sólo una -en la que tenía una participación minoritariaintegraba el ranking de las 200 empresas de mayor facturación de Argentina (Acevedo, Basualdo y Khavisse, 1990). Pero a partir de la compra de Sevel, no sólo pasó a controlar una de las principales firmas privadas del país -ocupaba el puesto 21 en 1983-, sino también a otras quince empresas distribuidas en los distintos eslabones de la cadena automotriz. A partir de entonces, Macri logró consolidar su presencia en el sector y pocos años después se transformaría en el principal fabricante de automóviles del país.

En el presente artículo se afirma que la clave de esta expansión estuvo en la capacidad del grupo para aprovechar la retirada del país de las grandes empresas transnacionales del sector. Para reconstruir la trayectoria de las empresas Fiat y Socma, se recurrió principalmente a entrevistas semiestructuradas a cinco exdirectivos. 7 artículos periodísticos de dos revistas empresariales (Mercado y Prensa Económica), así como a las notas recopiladas en el archivo del Centro de Estudios de la Situación y Perspectivas de la Argentina (CESPA) de la Facultad de Ciencias Económicas de la Universidad de Buenos Aires para el periodo 1976-1982, al Boletín Oficial -donde figura la información sobre la creación de empresas y cambios en los directorios de las firmas-, y una publicación institucional de la firma italiana Fiat Auto Argentina (2009). Para analizar el impacto de las políticas económicas en el desempeño del sector se utilizaron datos cuantitativos elaborados por la Asociación de Fabricantes de Automotores (ADEFA, 1990).

\footnotetext{
${ }^{4} \mathrm{Al}$ respecto, este artículo se enmarca en una serie de trabajos que, desde distintas perspectivas, estudia casos de empresas particulares en la industria automotriz. Destacan los trabajos de Bil (2017a) sobre Renault durante la década de 1980; de Cipolla (2014) sobre la fabricación de El Torino por parte de IKA a mediados de la década de 1960; de Harari (2009) sobre el paso de la estatal IAME a IKA, y de Harari y Bil (2017) y Donald (1988) sobre IKA o Katz (2009) sobre la producción del Ford Taunus durante la primera parte de la década de 1970.

${ }^{5}$ Los activos de Citröen fueron adquiridos por la firma autopartista local Industrias Eduardo Sal Lari (IES), que produciría algunos modelos de la marca durante la década de 1980.

${ }^{6}$ En Brasil se produjo un estancamiento en el mercado interno durante la década de los ochenta, pero Volkswagen, Ford, General Motors y Fiat conservaron su participación (sumadas, siempre representaron más de 98 \% de la producción) a lo largo de la década (Luedemann, 2003, p. 2). En México, las compañías estadunidenses incrementaron su presencia a partir de inversiones orientadas a hacer frente a la competencia japonesa y, en paralelo, el gobierno vendió a inversores extranjeros las acciones que tenía en dos firmas del sector, con lo cual terminó la inversión de capitales mexicanos en la industria terminal (Miranda, 2007).

${ }^{7}$ Para respetar su condición de anonimato, se los identifica de la siguiente manera: entrevistado 1: ex gerente financiero de Socma; entrevistado 2: ex técnico de proyectos de Socma y, luego, gerente de Sevel, y entrevistado 3: ex gerente de Fiat y Sevel.
} 
En un primer apartado, este trabajo analiza los cambios en la industria automotriz local y la estrategia de Fiat Argentina, para compararlos. A continuación, se exponen los principales aspectos del proceso de diversificación que experimentó el grupo Macri a partir de mediados de la década de los setenta, se analiza la retirada de Fiat y las características principales del acuerdo alcanzado con el grupo Macri. Por último, se exponen las consideraciones finales.

\section{LOS CAMBIOS EN LA INDUSTRIA AUTOMOTRIZ LOCAL Y LA RECONVERSIÓN DE FIAT ARGENTINA}

A fines de los setenta y comienzos de los ochenta la industria automotriz atravesó una profunda reconversión internacional que aceleró notablemente la integración mundial de la producción. Dicho proceso es producto, en primera instancia, de las crisis de la producción derivadas de la crisis del petróleo de 19738 y de la sobreproducción de vehículos de 1978 (Tarditi, 2000). A inicios de la década de 1980 los mercados estadunidenses y europeos pasaron de crecer de 12 a $13 \%$ anual, a tasas de 2 a $3 \%$ (Cohen, 1981, p. 391). Por su parte, la producción japonesa, que se había expandido aceleradamente con base en el modelo toyotista, estaba desplazando a Estados Unidos de su posición de liderazgo como productor mundial, imponiéndose en los mercados más importantes (CEPAL, 1987). De esta forma, los principales fabricantes de autos centraron su atención en los mercados dinámicos de los países en desarrollo y en la batalla por el mercado de los automóviles grandes (Gooding, 1979a y 1979b ; Cohen, 1981). En este contexto de reorganización internacional, que incluyó la racionalización de recursos, la incorporación de nuevas tecnologías y una fuerte competencia de las firmas estadunidenses y japonesas, las empresas europeas debieron rediseñar sus estrategias.9

Estos cambios afectaron considerablemente a Fiat, que luego de la segunda guerra mundial había experimentado una veloz recuperación enfocándose en la fabricación de autos pequeños y de precios bajos, primero en el mercado italiano y luego vía exportaciones e inversiones productivas en el extranjero (Casalino, 2010). La crisis del petróleo de 1973, los aumentos salariales de la etapa previa, la baja productividad ${ }^{10}$ y el estancamiento de la industria automotriz a nivel mundial pusieron a la empresa en una frágil situación financiere ${ }^{11}$ (Cohen, 1981; Volpato, 2001). De esta manera, se evidenció que la forma de producción fordista y en masa de automóviles pequeños y baratos había terminado para Fiat, de modo tal que emprendió un proceso de reorganización que comprendió la realización de nuevas adquisiciones y alianzas ${ }^{12}$ la reducción de la mano de obra,

\footnotetext{
${ }^{8}$ Por lo cual, la industria automotriz se ve obligada a alterar extraordinariamente el diseño de los automóviles por el gran aumento de los precios del petróleo y las nuevas regulaciones de la velocidad y la protección ambiental del gobierno de Estados Unidos, véase Cohen (1981).

${ }^{9}$ Por ejemplo, el número de empleados de las dieciséis automotrices más grandes de Europa disminuyó $3.5 \%$ entre 1973 y 1977 (Cohen, 1981, p. 402).

${ }^{10}$ A pesar de haber promovido disminuciones en su personal en la década previa. En 1977 disminuyó 32564 empleados desde un nivel máximo de 200575 de Fiat Italia en 1973 (Cohen, 1981, p. 402).

${ }^{11}$ Con el objetivo de conseguir fondos suficientes para superar dicha crisis, Fiat compartió parte de su paquete accionario con el Libyan Arab Foreign Bank. El acuerdo consistió en que el banco sólo tendría participación financiera, sin que los representantes de Muamar el Gaddafi se involucraran en las decisiones de la compañía (Volpato, 2001, p. 34).

${ }^{12}$ Se adquirieron las empresas especializadas en vehículos de alta gama Alfa Romeo, Maserati e Innocenti y se formó un joint venture con Ford Gran Bretaña (Volpato, 2001).
} 
la profundización de su organización multinacional basada en mercados regionales y una desintegración vertical, desprendiéndose de aquellas empresas que no eran lo suficientemente eficientes y registraban menores capacidades competitivas ${ }^{13}$ (Germano, 2007; Volpato, 2001).

En el plano regional, la industria automotriz de América Latina comenzó a atravesar el desmantelamiento de sistemas de sustitución de importaciones previos a la década de 1980, para abrirse, en mayor medida, a redes de producción y competencia internacional de las automotrices, que terminarán de configurarse en la década de 1990 con el establecimiento del Mercosur. En muchos casos, las operaciones locales de estas empresas se integraron a redes regionales y globales para alcanzar nuevas economías de escala $\sqrt{14}$ Además, la reorganización también afectó la actividad y la disposición de los tradicionales centros de la región, ya que las multinacionales adoptaron a Brasil y México como plataformas, debido a ciertas ventajas de costos por sobre Argentina (Bil, 2017b).

A partir de la crisis mundial de 1930, en Argentina se inicia un largo periodo caracterizado por controles de importación de vehículos y el intento de sustituir dichas importaciones de manufacturas por bienes producidos localmente (Nofal, 1989; Sourrouille, 1980). Así, luego de la segunda guerra mundial, las infantes empresas autopartistas, estimuladas por el peronismo, proveen con partes a las plantas ensambladoras de vehículos (Nofal, 1989). Después de un intento fallido de promover la sustitución de importaciones a partir de empresas estatales, en 1959 se abren las puertas del mercado argentino a las inversiones extranjeras, en plena coincidencia con lo que era un periodo de expansión transnacional de las grandes firmas que dominaban el mercado mundial de automóviles (Sourrouille, 1980). De esta forma, la tasa media anual de inversiones en el sector fue, entre 1960 y 1964, casi diez veces superior a la del periodo 1956-1959 (Baranson, 1971, p. 57).

La apertura al capital extranjero se hizo a partir de promover un modelo competitivo, con fuerte promoción estatal, orientado al mercado interno a través de la sustitución de importaciones y con base en empresas transnacionales (Sourrouille, 1980) ${ }^{15}$ Como resultado, se produce un desembarco masivo de empresas transnacionales en el entramado productivo y de nuevas terminales nacionales: empresas multinacionales ya instaladas (Ford, General Motors, Chrysler, Mercedes Benz, IKA) y aquellas que arribaron luego (como Renault, Citröen, Peugeot y Fiat), las cuales recibieron directamente los beneficios de la nueva legislación (Panigo, Lavarello, Monzón, Mancini y Langard, 2017). Luego, el régimen automotriz sancionado en 1971 reforzó el contenido nacional de los vehículos e introdujo la preocupación por la apertura exportadora ${ }^{16}$ estableciendo $50 \%$

\footnotetext{
${ }^{13}$ En 1986 el grupo tenía 100 firmas controladas y vinculadas, mientras que en 1987 se registraron 84 (Volpato, 2001, p. 62).

${ }^{14}$ Según Shaiken (1995, p. 24), Argentina, por ejemplo, pasó de exportar 1 \% de su producción (3 600 vehículos) en 1980 a 9 \% (30 000 vehículos) en 1993, lo cual se vinculó, a su vez, a la caída de la absorción doméstica de la producción.

${ }^{15}$ Es así como, entre los años 1958 y 1959, se aprueban las leyes de inversiones extranjeras directas (Ley 14.780) y de promoción industrial (ley 14.781), con el objetivo de coordinar la iniciativa público-privada y otorgar ventajas a las empresas radicadas en el territorio nacional. A su vez, esto se combinó con la existencia de tasas negativas en términos reales en el mercado financiero en todo el periodo (Kosacoff, Vispo y Todesca, 1991, p. 5).

${ }^{16} \mathrm{Al}$ respecto, Amico (2011) recupera dicha preocupación en los principales teóricos del estructuralismo como Raul Prebisch, Fernando H. Cardoso, Marcelo Diamand, entre otros. Sobre estas preocupaciones de la política económica de la época, véanse Katz y Ablin (1977) o Teitel y Thoumi (1986).
} 
de reintegro sobre las ventas externas. Con una intensa promoción gubernamental, este incentivo generó una importante expansión de las exportaciones, fundamentalmente orientadas al mercado latinoamericano (Barbero y Motta, 2007) 17

De este modo, el complejo automotor pasó a tener una posición de liderazgo dentro de la actividad industrial, manifestando, entre 1960 y 1974, alrededor de $9 \%$ del total del valor agregado por la producción manufacturera y una proporción aún mayor del empleo (Barbero y Motta, 2007, p. 190). Al respecto, el personal ocupado en el sector creció de 9900 trabajadores en 1959 a 57400 en 1974 (véanse gráficas 1 y 2).

No obstante, el fuerte crecimiento en la producción durante este proceso no logró alterar sustantivamente algunos rasgos básicos de la industria, como la existencia de modelos de vehículos obsoletos en términos internacionales, baja competitividad de los productos, y escasa actualización tecnológica (Kosacoff, Vispo y Todesca, 1991, p. 5) ${ }_{18}^{18}$ Dicho atraso en el nivel tecnológico de la industrial local durante la etapa del desarrollo del sector automotriz argentino se debió, en gran medida, a una pequeña escala relativa de producción que dificultaba la incorporación de técnicas avanzadas, ya que demandaría inversiones que sólo podrían ser absorbidas para niveles de producción muy superiores (Baranson, 1971 pp. 46-48; Nofal, 1989, pp. 89-94; Sourrouille, 1980, p. 121) 19

La irrupción de la última dictadura militar argentina modificó sustancialmente el sendero de esta rama industrial, debido a las reformas estructurales instauradas en el conjunto de la economía, las cuales se llevaron a cabo con el objetivo específico de alcanzar una inserción competitiva de Argentina en los mercados mundiales; sin embargo, implicaban el propósito mayor de remover la estructura económica-social que dio sustento al proceso de industrialización anterior (Nochteff, 1991; Schorr, 2012).

La conjunción de la represión salarial de 1976 con la reforma financiera de 1977, la arancelaria y el endeudamiento externo, derivados de la apertura de 1979, interrumpió el modelo sustitutivo anterior. De esta forma, en los años posteriores a 1976 se produjo el cierre de más de 20000 establecimientos fabriles, el producto bruto del sector cayó cerca de $20 \%$ entre 1976 y 1983, la ocupación disminuyó en forma pronunciada, y se redujo el peso relativo de la actividad en el conjunto de la economía (pasó de 28 a $22 \%$ del PBI) (Schorr, 2012, p. 36). No obstante, dichos efectos fueron dispares según las distintas ramas del sector, de tal manera que aquellas ubicadas en las primeras etapas del procesamiento manufacturero, dedicadas a la elaboración de commodities y caracterizadas por el predominio de estructuras de mercado altamente concentradas y/o al aprovechamiento de los regímenes de promoción industrial puestos en práctica durante esta etapa, mejoraron su posición en la economía argentina (Schorr, 2012).

Al nivel sectorial, también se produjo un importante giro en la orientación de las políticas públicas. En 1979, el gobierno militar sancionó la ley 21.932, con el fin de "insertar al sector productor dentro del orden económico general, posibilitar su mejoramiento tecnológico, permitir

\footnotetext{
${ }^{17}$ Entre 1971 y 1976 se exportaron alrededor de 59000 unidades, lo que junto a crecientes exportaciones de autopartes generaron, en esos años, un balance comercial predominantemente superavitario (Kosacoff, Vispo y Todesca, 1991 , p. 5).

${ }^{18}$ Incluso, dichas características se reforzaron, incluso hasta la década de 1990.

${ }^{19} \mathrm{Katz}$ (2009) relativiza los enfoques que señalan el atraso tecnológico en el sector durante dicho periodo, sosteniendo que a mediados de la década de 1970 fue el punto culminante del proceso evolutivo de la industria de posguerra, al haberse desarrollado un nivel tal de capacidades técnicas locales que no volvería a repetirse en el modelo productivo que le sucedería.
} 
CUADRO 1. Densidad de vehículos por habitante

\begin{tabular}{lccc}
\hline Años & $\begin{array}{c}\text { Población } \\
\text { (en miles) }\end{array}$ & $\begin{array}{c}\text { Vehiculos } \\
\text { totales }\end{array}$ & $\begin{array}{c}\text { Habitantes } \\
\text { por vehiculo }\end{array}$ \\
\hline 1955 & 19071 & 601681 & 31.7 \\
1960 & 20083 & 865536 & 23.2 \\
1965 & 21644 & 1487948 & 14.5 \\
1970 & 23908 & 2269417 & 10.5 \\
1975 & 25551 & 3328102 & 7.7 \\
\hline
\end{tabular}

Fuente: Nofal (1989).

\section{GRÁFICA 1. PRODUCCIÓN (EJE IZQUIERDA), IMPORTACIÓN Y EXPORTACIÓN (EJE DERECHA) DE VEHÍCULOS TERMINADOS (1959-1989)}

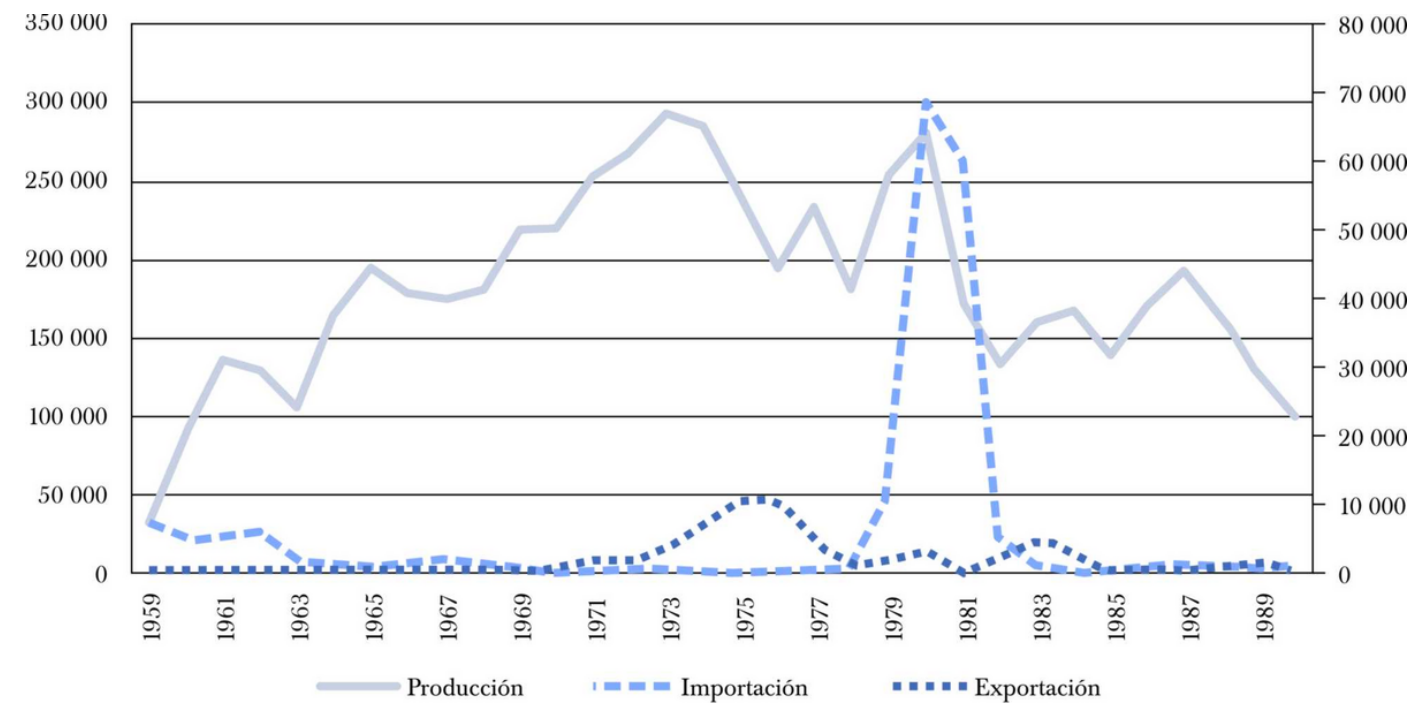

Fuentes: Sourrouille (1980) y Morero (2013).

la apertura de mercados de exportación, e inducir una creciente competitividad interna y externa" (Presidencia de la Nación, 1979). Como parte del paquete de medidas se ampliaron los contenidos importados permitidos, se autorizó la importación de vehículos terminados, y se eliminó toda restricción a la integración vertical de las empresas terminales. El resultado más visible de dichas medidas, que estuvieron acompañadas por el establecimiento de un tipo de cambio fijo atrasado, fue un fuerte crecimiento de las importaciones: de 460 unidades importadas en 1978 a más de 68000 en 1980, lo que representó 20 \% del consumo interno (Barbero y Motta, 2007, p. 209). Si bien dicha apertura se mantuvo sólo hasta 1981, la adaptación de las terminales a este nuevo esquema de reglas de juego implicó su virtual transformación en agentes importadores, favorecido por el alto nivel de precios internos, alejados de los niveles internacionales (Morero, 2013).20

\footnotetext{
${ }^{20} \mathrm{El}$ mecanismo de selección forjado por el gobierno dictatorial premiaba conductas comerciales de importación y especulativas, y el desarrollo de competencias en estas actividades (Morero, 2013).
} 
GRÁFICA 2. PERSONAL OCUPADO EN EL SECTOR AUTOMOTOR (1959-1989)

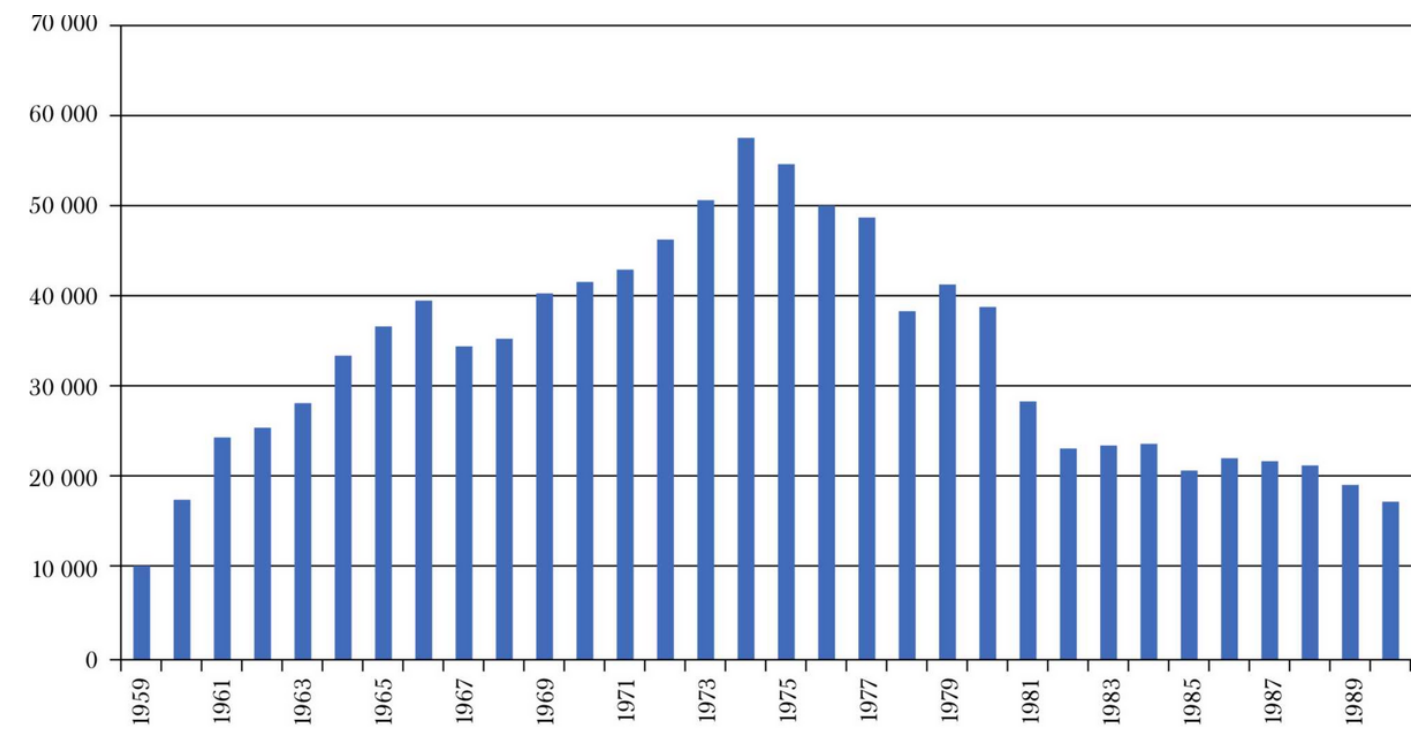

Fuente: ADEFA (1990).

Otro de los aspectos salientes de transformación de este periodo fue el fuerte aumento de la proporción de partes y componentes importados en los vehículos producidos nacionalmente. El contenido importado por unidad producida se duplica de 1973 a 1979 (alrededor de 300 dólares) y se triplica a 1980 (supera los 1000 dólares por unidad) (Morero, 2013, p. 20). El nivel promedio de contenido importado se triplica entre 1973-1980 y 1980-1990, desde alrededor de 500 dólares por unidad a más de 1500 dólares por unidad (Morero, 2013, p. 20), teniendo severos efectos en el eslabón autopartista.

Ante esta situación, la prensa especializada se pronuncia:

La oferta se diversificó de una manera explosiva, incorporando más de veinte marcas extranjeras, y las empresas nacionales, en plena etapa de reestructuración, no perdieron su nivel, pero se apoyaron, en general, en los modelos conocidos [...]. Ubicadas en este punto del recorrido, las terminales argentinas contemplan con preocupación el claro avance de la importación, favorecido hasta el momento por la paridad cambiaria e incapaz de ser frenado por un régimen de protección que no alcanza para eliminar desfasajes arancelarios respecto de las autopartes de procedencia extranjera 21

$\mathrm{Al}$ respecto, la vicepresidente de Renault Argentina, Jacques Monbeig, señalaba: "el aguijón clavado por la competencia extranjera pudiera convertirse en un puñal, si ningún medio fuera arbitrado para repeler sus efectos" "22 De la misma forma, "los directivos máximos de las empresas Renault Argentina y Sevel S. A. coincidieron en que sus reiteradas advertencias sobre los peligros que entraña para la industria terminal automotriz instalada en el país la penetración indiscriminada de vehículos importados" ${ }^{23}$

${ }^{21}$ Automotores. Los nacionales ponen primera, Prensa Económica, 1 de abril de 1981, p. 36.

${ }^{22}$ Automotores. Los nacionales ponen primera, Prensa Económica, 1 de abril de 1981, p. 36.

${ }^{23}$ Industria: autos, Prensa Económica, 25 de mayo de 1982, p. 21. 


\section{CUADRO 2. DISCONTINUACIONES Y PRESENTACIONES DE MODELO POR MARGA}

\begin{tabular}{ccccc}
\hline & \multicolumn{1}{c}{ Ford } & \multicolumn{1}{c}{ Volkswagen } & \multicolumn{1}{c}{ Renault } & \multicolumn{1}{c}{ Sevel } \\
\hline \multirow{5}{*}{$\begin{array}{c}\text { Coronado (1980) } \\
\text { heredados }\end{array}$} & & Peugeot 404 (1980) \\
-tinuaciones & Fairlane (1981) & de Chrysler & Torino (1982) & Fiat 128 (1981) \\
& Taunus (1984) & 1500 (1982) & R4 (1986) & $(1982)$ \\
& & & & Fiat 147 (1981) \\
& & VW 1500 & Coupé Fuego & Europa y Súper \\
& & $(1982)$ & $(1982)$ & $(1982-1983)$ \\
Presentaciones & Ford Sierra & VW Gacel & R11 (1984) & Regatta (1985) \\
& $(1984)$ & $(1983)$ & R9 (1987) & Brío y Duna (1987) \\
\hline
\end{tabular}

Fuente: Bil (2017b).

Asimismo, la caída del salario real, que se agravó con el colapso del programa económico de Martínez de Hoz, donde perdió más de 40 \% de su valor entre el pico de 1974 y 1983 (Bil, 2017a, p. 99), también generó una fuerte caída en las ventas de automóviles, principalmente en los modelos más económicos. El segmento de autos pequeños, que había experimentado el crecimiento más acelerado en la década previa, se redujo de forma drástica. La venta se concentró en medianos y de gama alta, correspondientes a sectores de mejores ingresos (Bil, 2017b, p. 301). Así, durante los años de la dictadura, desde 1976 a 1982, la producción de vehículos cayó 36\%, lo que representó en 1982 (123 200 unidades) casi la mitad de la producción de 1975 (240 000 unidades) (Morero, 2013, p. 18).

Ante las consecuencias negativas que tuvieron estos cambios macroeconómicos e institucionales en el sector industrial y su rama automotriz, sumado a la reestructuración internacional del sector, las firmas del complejo automotor rediseñaron sus estrategias empresariales ${ }^{24}$ Entre ellas, cabe mencionar el cambio de enfoque de la producción de automóviles chicos por grandes (véase cuadro 2), el redimensionamiento y reorientación de la oferta, la racionalización de la mano de obra ${ }^{25}$ la presentación de nuevos modelos o el retiro de la mayoría de los antiguos ${ }^{26}$ Por otra parte, algunas empresas del sector tomaron un camino más radical retirándose del país, como General Motors en 1978 o Citröen en 1979, o la transferencia de la operación de Chrysler a Volkswagen en 1980.

Frente a este panorama, la filial argentina de Fiat también debió embarcarse en un proceso de reestructuración en sintonía con los cambios de la firma al nivel internacional. La actividad inicial de Fiat en Argentina estuvo vinculada con la actividad agrícola a través de Agromecánica

\footnotetext{
${ }^{24}$ Fitzsimons y Guevara (2018) sostienen que el periodo de crisis y contracción entre fines de la década de 1970 y comienzos de la de 1990 se debió a la combinación de la creciente brecha tecnológica, de escala y productividad y el estancamiento de la magnitud de renta agraria disponible como fuente de compensación. A su vez, Bil (2017b) discute con las interpretaciones que se centran en la apertura comercial de la dictadura militar (CEPAL, 1987) para sostener que el mayor peso de la crisis es producto del estancamiento y la reconversión de las firmas a nivel internacional, principalmente, las firmas estadunidenses y europeas.

${ }^{25} \mathrm{El}$ empleo se redujo casi $50 \%$ en tres años: de 41200 en 1979 a 28300 en 1981 (Bil, 2017b, p. 305).

${ }^{26}$ Automotores. Los nacionales ponen primera, Prensa Económica, 1 de abril de 1981, p. 36.
} 
SACIF para la comercialización, importación y asistencia técnica de tractores Fiat. En 1959 realiza su radicación industrial a partir de la construcción de una planta en la localidad de Caseros que fabricaría los primeros Fiat 600 D. A inicios de 1970 la firma lideraba la producción automotriz en Argentina (véase gráfica 3) y poseía una amplia estructura que abarcaba diferentes rubros: como el de tractores, grandes motores diesel, material rodante ferroviario, camiones y automóviles; sin embargo, a pesar de dicha diversificación, durante su época de esplendor -entre fines de la década de 1960 y principios de la de 1970-, la estructura de Fiat Argentina se caracterizó por un alto grado de concentración del poder y centralización de las decisiones. La mayoría de estas pasó por su director general, Oberdan Sallustro, secuestrado y asesinado en 1972 por la agrupación guerrillera Ejército Revolucionario del Pueblo.

Las transformaciones de la segunda mitad de la década de 1970 obligaron a Fiat a emprender el proceso contrario y, de esta forma, alinearse a las políticas de descentralización operativa y societaria iniciadas por la casa matriz en 1979. En este sentido, se constituye la sociedad Fiat Argentina SACIF ${ }^{27}$ la cual asume las actividades vinculadas con la producción y comercialización de automóviles, en tanto Fiat Diesel S. A. absorbe las divisiones de Camiones, Tractores, Material Ferroviario, Grandes Motores Diesel y el Centro de Actividades Termodinámicas, y en 1981 se escinden para dar nacimiento a Fiat Vehículos Industriales (a partir de 1982 pasará a llamarse Iveco), Fiat Materfer, Fiat Tractores, Fiat C. A. T. y Grandes Motores Diesel (Fiat Auto Argentina, 2009, p. 160). Luego de la descentralización de la estructura se llevaron adelante procesos de ajuste en algunas de las firmas, empezando por la fábrica de tractores.

Cabe señalar que la reconversión y el posterior ajuste de Fiat en el país se da muy poco tiempo después del desembarco de la multinacional en Brasil, mercado que se encontraba en pleno crecimiento (véase gráfica 4). Fiat Automóviles comienza sus operaciones oficialmente en Brasil en 1976 28 inaugurando la fábrica de Betim (Minas Gerais) ${ }^{29}$ la primera ensambladora de autos que se instaló fuera de San Pablo (Carvalho y Bernardes, 1998). Esta reorientación también trajo aparejado un importante cambio a nivel regional: la creación de una dirección latinoamericana, con sede en Río de Janeiro, que adoptó las decisiones que previamente se concretaban desde Turín (sede central) ${ }^{30}$ Este proceso se da concomitantemente con una expansión de la producción automotriz brasileña en comparación con la argentina, que de fabricar cantidades similares a mediados de 1960 termina produciendo cuatro veces más hacia fines de 1980.

La expansión en Brasil contrastaba con la política de no invertir prevista para Argentina. Así, "en noviembre de 1980 Giovanni Agnelli anunció a los accionistas en Turín la decisión de encarar un 'drástico redimensionamiento' de la presencia industrial de Fiat en el país, una escisión madurada frente a la inestabilidad económica y política que reinaba entonces en la Argentina y la necesidad de privilegiar la consolidación y desarrollo del Grupo en Europa y en mercados que aseguraban más potencialidades de crecimiento" (Fiat Auto Argentina, 2009, p. 162).

Un hito importante en este proceso de ajuste fue la réplica del acuerdo realizado en Europa (1979) entre Fiat y Peugeot para encarar la producción conjunta de vehículos comerciales livianos, a raíz de la creciente competencia estadunidense y japonesa, creando Societá Europea Veicoli

\footnotetext{
${ }^{27}$ Posteriormente, Fiat Automóviles S. A.

${ }^{28}$ La construcción de dicha planta comenzó en 1973, implicando un gran esfuerzo financiero para Fiat (Casalino, 2010).

${ }^{29}$ Dicho emprendimiento realizado en conjunto con el Estado de Minas Gerais, el cual, en 1986 se retira de la empresa, lo cual también impulsa a Fiat a intervenir en mayor medida en dicho mercado (Volpato, 2001).

${ }^{30}$ Reorganización de Fiat Concord a nivel latinoamericano, El Cronista Comercial, 24 de noviembre de 1978, p. 41.
} 


\section{GRÁFICA 3. PRODUCGIÓN ANUAL DE LAS PRINCIPALES EMPRESAS AUTOMOTRICES}

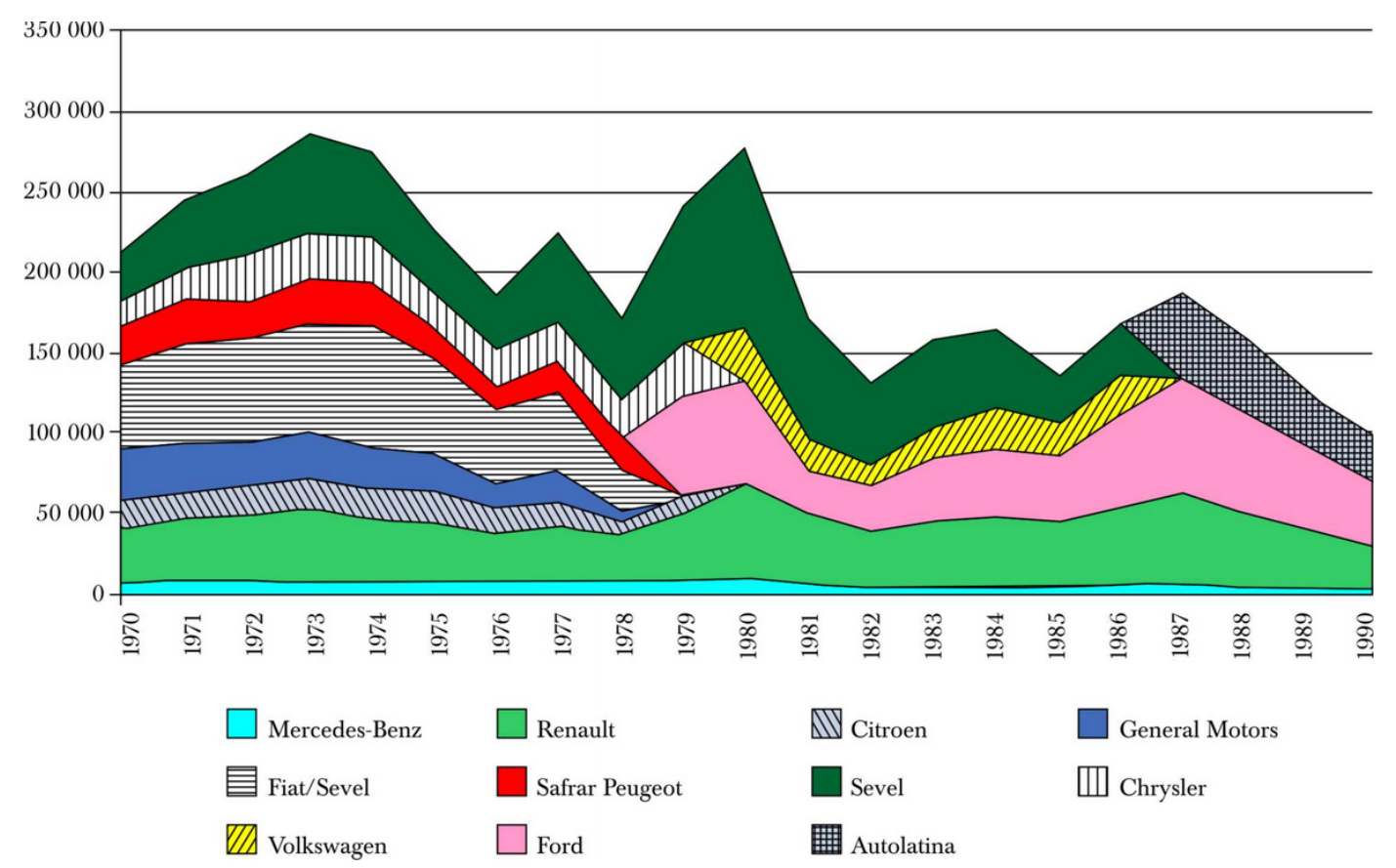

Fuente: ADEFA (1990).

Leggeri (Sevel). De esta forma, el 28 de febrero de 1980 se concreta un acuerdo preliminar entre el presidente de Peugeot-Citroën, Jean Paul Parayre, y el vicepresidente ejecutivo de Fiat Società per Azioni, Umberto Agnelli, que contempló la fusión de las terminales argentinas Safrar-Peugeot y Fiat.

En un contexto de fuerte contracción del mercado local, el principal argumento esgrimido por los protagonistas fue la complementariedad productiva entre ambas firmas. Fiat fabricaba vehículos de pequeños hasta medianos, pero concentrando casi los dos tercios de su producción en los pequeños a medio-medianos; mientras que Safrar-Peugeot se caracterizaba por producir vehículos de medianos a medianos-grandes ${ }^{31}$ Sin embargo, como se verá más adelante, la fusión no tendría los resultados esperados, y la profundización de la crisis local obligaría a Fiat a tomar medidas más radicales.

\section{La estrategia de diversificación del Grupo Macri y la AdQuisición de Sevel}

A principios de la década de 1980, cuando Fiat Argentina estaba instaurando el proceso de reestructuración, el grupo Macri se encontraba en plena expansión a través de la diversificación de sus actividades desde un origen vinculado a la construcción. Su presencia en el sector se había iniciado a fines de la década de 1950, cuando Francisco Macri, inmigrante italiano llegado a Argentina en la década de 1940, fundó, junto con su hermano Antonio, una pequeña firma constructora para

${ }^{31}$ Empresas: Fiat-Peugeot la vida en común, Revista Mercado, 1 de enero de 1981. 


\section{GRÁFICA 4. EVOLUCIÓN DE LA PRODUCGIÓN DE VEHÍCULOS BRASIL Y ARGENTINA (1965-1997)}

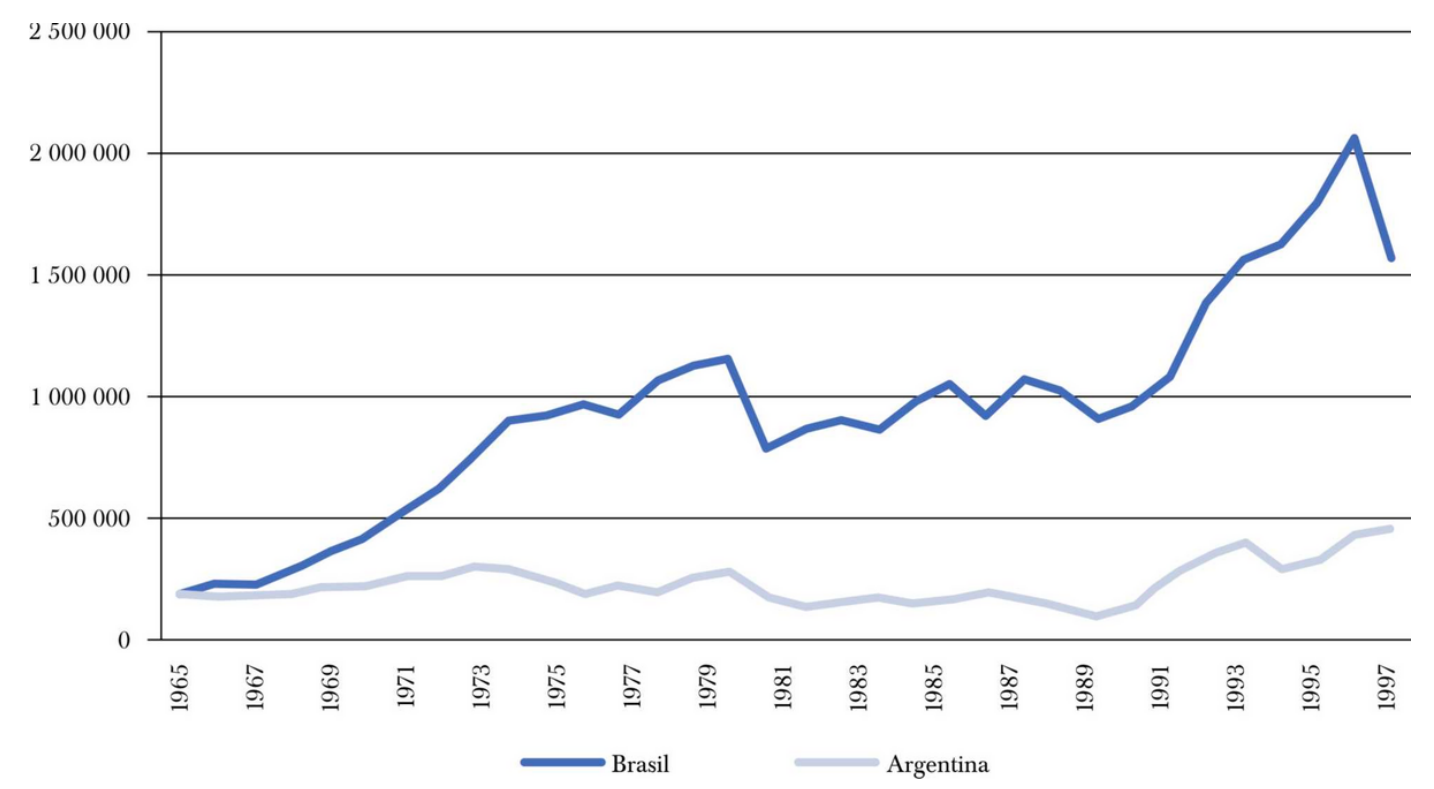

Fuente: Tarditi (2000).

ser subcontratista en la fabricación de silos y elevadores de granos. La empresa se llamó Demaco S. A., creada el 25 de abril de 1960. El directorio inicial estuvo compuesto por Adolfo De Ambrosi, presidente; Francisco Macri, vicepresidente; Juan Carlos Vivo y Ángel Nardelli, directores titulares 32

Meses más tarde, la empresa logró hacerse cargo del contrato de construcción del puerto de la ciudad de Mar del Plata, que se transformó en su primera gran obra y le permitió ganar antecedentes e integrar los listados de contratistas principales de proyectos de obra pública (Macri, 1997). En 1964, Demaco S. A. se transformaría en Silos Demaco y Compañía Sociedad Anónima (Sidecos). Pero el gran hito se daría unos años más tarde cuando esta se asoció con Impresit, la empresa constructora multinacional controlada por el grupo Fiat para formar Impresit Sideco, que se transformaría durante la década de 1960 en un protagonista del sector de la construcción en el país.

Impresit, por su parte, había nacido en Italia, en 1929, con el nombre de Imprese Italiane all'Estero, con el objetivo inicial de aprovechar las oportunidades que brindaban tanto las inversiones en servicios púbicos como la construcción de grandes obras de ingeniería fuera de las fronteras italianas. ${ }^{33}$ En la década de 1960, la empresa incursionó en países de América del Sur como Ar-

\footnotetext{
${ }^{32} \mathrm{El}$ capital social fue de 10000000 de pesos moneda nacional y los accionistas iniciales de la empresa fueron miembros de las familias Vivo, Macri, De Ambrosi y Nardelli. Por parte de la familia Macri figuraron, además de Francisco, Alicia Blanco Villegas (esposa), Antonio Macri (hermano) y Jorge Macri (sobrino). Boletín Oficial, 19 de mayo de 1960.

${ }^{33}$ En sus inicios la empresa fue propiedad de tres bancos: Banco di Roma, Crédito Italiano y la Banca Nazionale di Crédito. Dos años más tarde, la crisis económica internacional llevó a que los accionistas mayoritarios cedieran sus participaciones al holding estatal Instituto per la Ricostruzione Industriale, que finalmente las transferiría a Fiat (Barjot,
} 
gentina y Chile, que experimentaban un fuerte crecimiento económico. ${ }^{34}$ En 1960 se creó en Argentina Sycic Impresit Empresas Asociadas a partir de la fusión de la empresa constructora Sycic y de la Impresse Italiane All'Stero Società per Azioni (Impresit). Un año más tarde, las mismas firmas fundaron Impresit Sycic Vial S. A., que durante los años siguientes tendría un protagonismo en la construcción de rutas (Castellani, 2009). En mayo de 1969 Impresit Sycic Vial se fusionó con Sideco para formar Impresit Sideco Sociedad Anónima. 35

La empresa participó en importantes proyectos de infraestructura durante los primeros cinco años, que incluyeron puentes, autopistas y elevadores de granos ${ }^{36}$ La firma también fue beneficiada con las grandes obras de infraestructura que llevó adelante el gobierno de facto de Juan Carlos Onganía. Sus principales contratos estuvieron asociados a la edificación de centrales nucleares: el grupo participó en la construcción de las plantas de Atucha (Buenos Aires) y Embalse (Córdoba) 37

Durante la década de 1970, a medida que la situación macroeconómica empeoraba, el grupo incursionó en negocios inmobiliarios, principalmente en la ciudad de Buenos Aires ${ }^{38}$ Durante esa etapa, construyó importantes edificios de oficinas en la zona del microcentro porteño 39

A mediados de la década de 1970 se produjo un punto de inflexión en el desarrollo del grupo: la creación del holding Socma y el pasaje de una firma constructora a un grupo económico diversificado. A partir de las consecuencias negativas que la inestabilidad económica provocaba en la industria de la construcción, Macri (19979 decidió comenzar a incursionar en otras actividades:

La posibilidad de continuar creciendo solamente con base en la construcción parecía extremadamente difícil [...]. La solución, que se transformó en una obsesión para mí, era diversificar, y no sólo geográficamente. Entre 1974 y 1976 me mantuve en guardia, buscando oportunidades interesantes en otros sectores, al principio en negocios relacionados con la construcción, pero siempre con el objetivo de diversificarme, es-

2002). Durante sus primeros años, la empresa participó en proyectos en Turquía y Portugal, pero fue recién con la construcción del ferrocarril Transiraní que Impresit comenzó a ganar fama mundial como contratista de grandes obras de infraestructura. Luego de la segunda guerra mundial, la firma, además de participar de la reconstrucción de Italia, llevó adelante grandes proyectos en África -concentrándose principalmente en rutas y represas-, beneficiándose del financiamiento internacional controlado por países occidentales.

${ }^{34}$ La importancia que tenía la región para la empresa creció notablemente durante aquellos años, mientras que el periodo 1955-1960 explicaba 15\% del total de obras desarrolladas fuera de Italia, proporción que pasó a $36 \%$ para 1966-1970 (Barjot, 2002, p. 265). En la mayoría de los casos tuvo como estrategia asociarse con empresas locales.

${ }^{35}$ Boletín Oficial, 13 de mayo de 1969.

${ }^{36}$ Impresit-Sideco participó como contratista principal o subcontratista de las siguientes obras: Puente General Belgrano (une las localidades de Chaco y Coerrientes), Central Termoeléctrica Luján de Cuyo (1967), elevador terminal de granos del Puerto de Ingeniero White (1965), Autopista Sante Fe-Rosario (1966), entre otras (Macri, 1997, p. 85).

${ }^{37} \mathrm{La}$ empresa ganadora de la licitación de la central de Atucha fue la empresa alemana Siemmens, que subcontrató a un consorcio encabezado por Impresit-Sideco e integrado por Hopchtief Ag de Alemania y Fiat Concord de Italia. En el caso de la planta de Embalse la firma obtuvo el contrato de las obras civiles asociada a la canadiense Atomic Energy of Canada Limited y a la italiana Italimpianti (Macri, 1997, p. 91).

${ }^{38}$ Según Macri (1997, p. 99): “Frente a una Argentina que en la búsqueda de una salida democrática parecía sumirse en el caos, concentré mis esfuerzos en mantener Sideco a flote y, como todos los demás, en estar siempre un paso delante de la inflación, Lo primero me llevó a buscar oportunidades poco usuales en el sector inmobiliario y en el mercado de la construcción privada, y lo segundo, a mantener líquida la mayor cantidad de nuestro patrimonio."

${ }^{39}$ A mediados de la década de 1970 se construyeron las torre Catalinas Norte y el edificio Madero, sobre la avenida L. N. Alem de la Capital Federal. 
pecialmente hacia los servicios. Era el momento ideal porque la crisis argentina estaba ahuyentando muchas inversiones extranjeras y podían comprarse empresas por poca plata y con buenas financiaciones (p. 107).

Francisco Macri se separó de sus antiguos socios en Demaco, conservó su participación en Impresit-Sideco y obtuvo el control del Banco de Italia y Río de la Plata, aunque la apuesta duraría poco tiempo (Macri, 1997; Cerruti, 2010). El paso definitivo lo daría en enero de 1976 con Socma, la empresa holding que funcionaría como nave nodriza del grupo durante las decadas siguientes. ${ }^{40}$ En el directorio inicial del holding, Macri fue secundado por tres figuras que tendrían un papel central en el grupo: Jorge Haiek, Ricardo Zinn y Jorge Blanco Villegas.

Jorge Haiek, vicepresidente de Socma en los primeros años, era un economista ligado al peronismo que se había desempeñado como secretario de Energía en 1971, acompañando la gestión de Aldo Ferrer en el Ministerio de Economía. Haiek tendría un papel central en el armado del holding y diseñaría el desembarco del grupo en el sector energético. Ricardo Masueto Zinn también se desempeñó en el gabinete ministerial de Ferrer como subsecretario de Coordinación y, luego, durante el gobierno de María Estela Martínez de Perón llegó a ser viceministro en la gestión de Celestino Rodrigo. Luego de abandonar la función pública pasó a ser directivo del Banco del Río de la Plata en representación del grupo de inversores que integraba Francisco Macri, y durante los años siguientes integraría el directorio de Socma, para luego transformarse en el principal directivo en Sevel. El tercer hombre que integró el directorio de Socma desde sus inicios fue Jorge Blanco Villegas, cuñado de Francisco Macri, quien participaba en la dirección del grupo desde fines de la década de 1960.

Durante sus primeros años, Socma reclutó a un conjunto de profesionales de origen diverso -muchos ligados al peronismo en los años anteriores, que se acercaron a través de Haiek-, que se encargó de buscar nuevos negocios en distintas áreas. El holding aprovechó las oportunidades que brindaron los procesos de privatización periférica del gobierno de facto. Sirviéndose de la experiencia de Haiek en el sector energético, se participó en la apertura del sector petrolero a la actividad privada que llevó adelante la dictadura militar. En 1977 fundó la empresa petrolera Pluspetrol junto al empresario Luis Alberto Rey, y en 1981 creó Petrolera Magallanes Este (véase cuadro 3). Sin embargo, ninguna de las inversiones prosperó en el mediano plazo 41

Luego de hacer incursiones en el sector industrial ${ }^{42}$ el grupo tuvo éxito en la diversificación hacia otro sector que estaba atravesando un proceso de privatización: el servicio de recolección de residuos de la ciudad de Buenos Aires. Manliba, un joint venture formado por Impresit Sideco y la firma estadunidense Waste Management International Inc., ganó la licitación que llevó adelante el intendente y militar Osvaldo Cacciatore. En 1981 el grupo también se hizo cargo del mismo servicio en la ciudad de Córdoba, a través de la empresa Aseo. Durante ese periodo también se

\footnotetext{
${ }^{40}$ Socma fue creada el 23 de junio de 1976 y su directorio inicial estuvo formado por Francisco Macri (presidente), Jorge Haiek (vicepresidente), Jorge Blanco Villegas, Ricardo Zinn, Edgardo Próspero Poyard y Diego Arria. Si bien una de las princiales apuestas siguió estando en la construcción -el proyecto de edificar un emprendimiento en la ciudad de Nueva York, que finalmente quedó abortada-, el mayor crecimiento se produjo a través de una importante diversificación de actividades.

${ }^{41}$ El grupo terminó vendiendo Pluspetrol a Rey poco tiempo después.

${ }^{42}$ Entre 1977 y 1979 el grupo también buscó insertarse en sectores industriales que eran beneficiarios de la política de promoción industrial. En el sector petroquímico creó junto con el empresario petrolero Alejandro Bulgheroni la firma Fenargen -de la cual se desprendería poco después-, y en la fabricación de pasta celulosa participó en Papedel junto a Luis Alberto Rey. Ninguna de esas iniciativas serían relevantes en la estructura del grupo.
} 


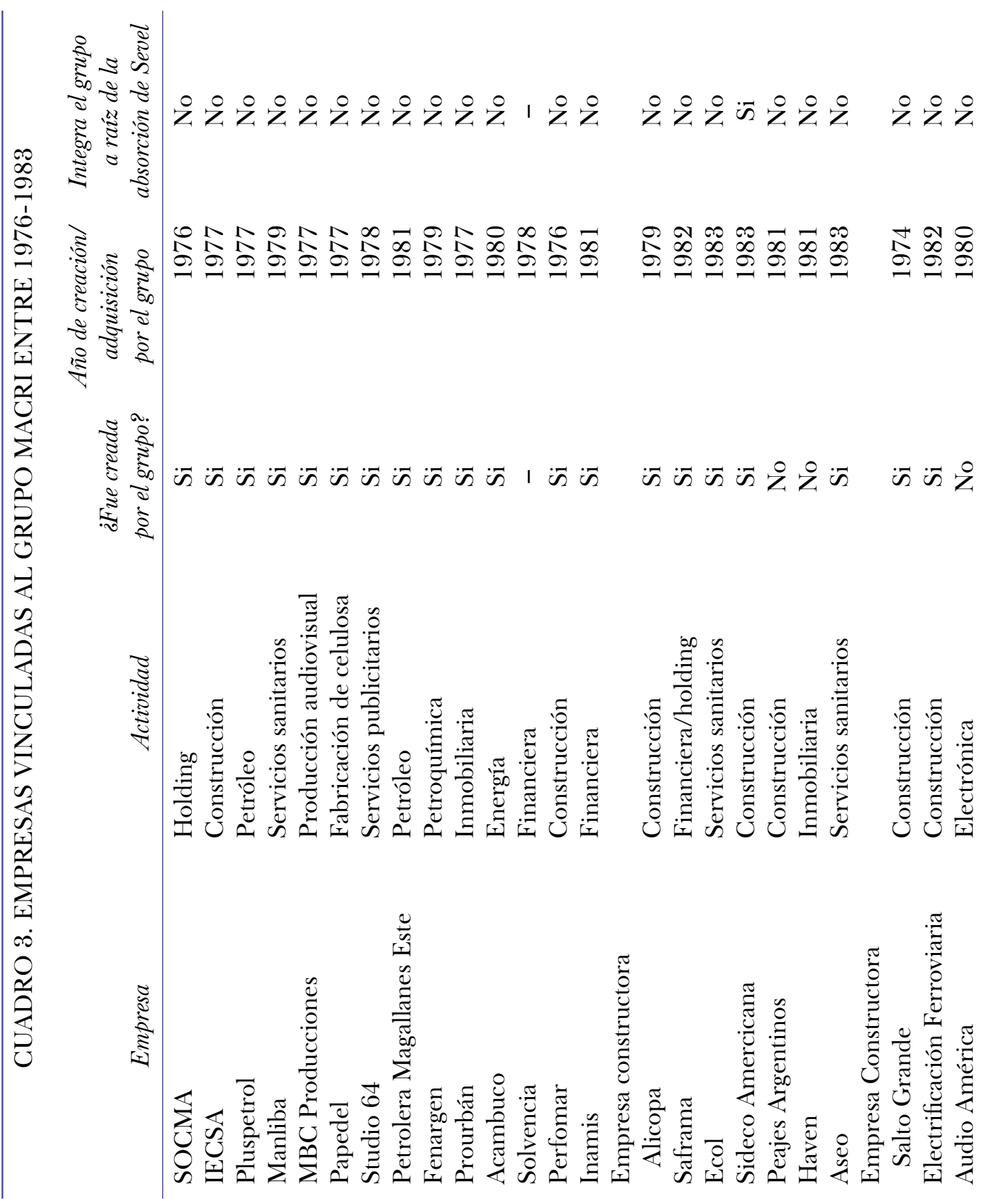




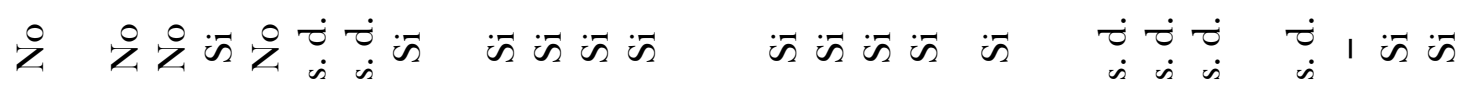

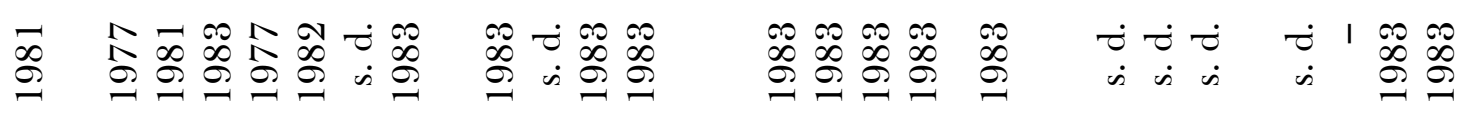

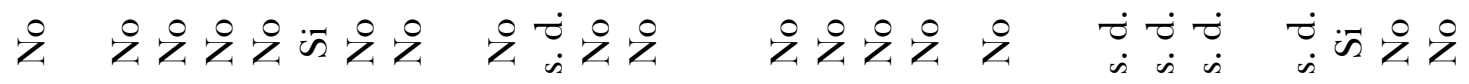
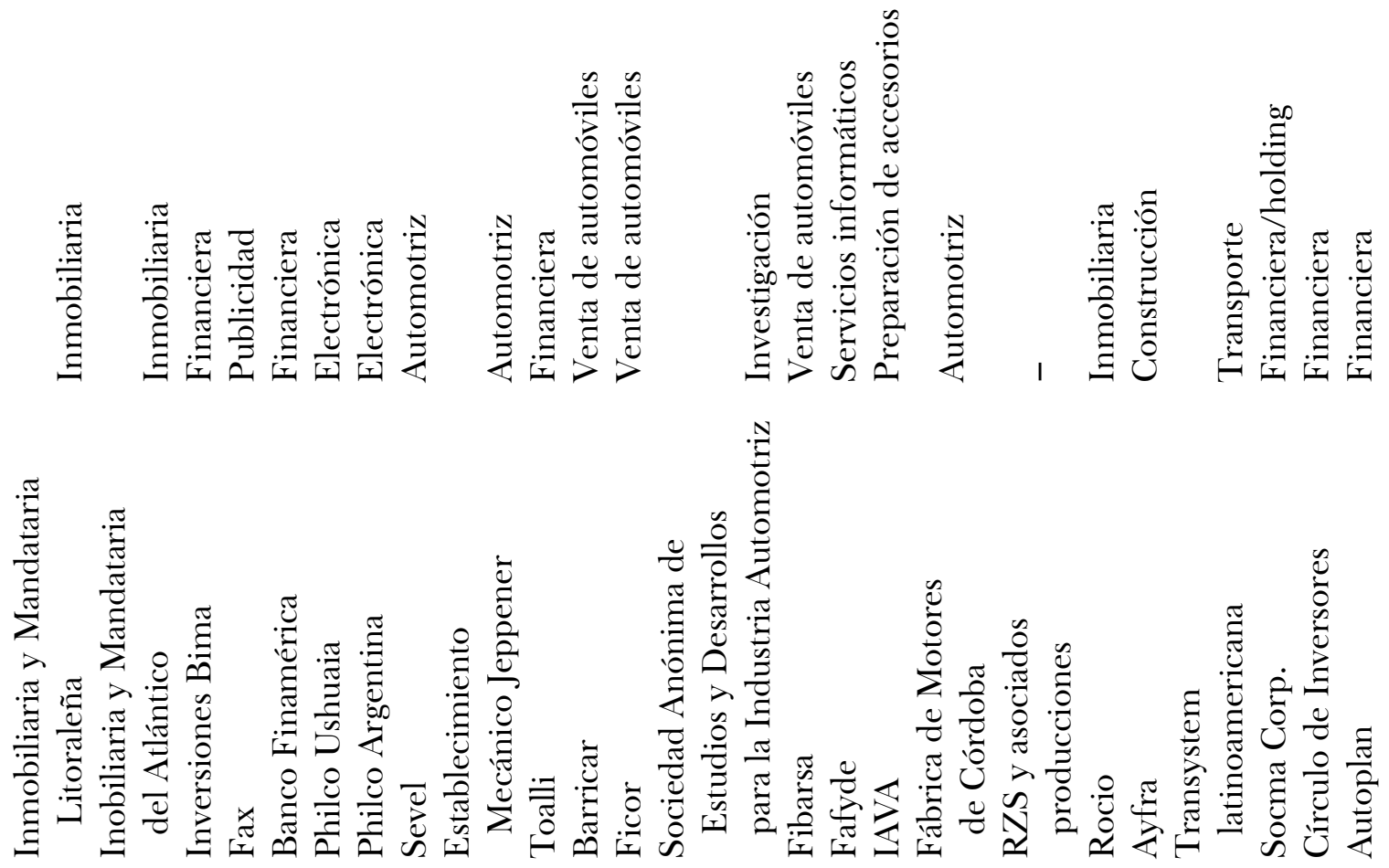


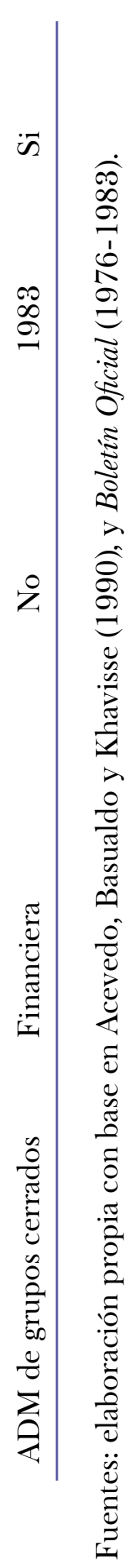


analizó la adquisición de la empresa Líneas Aéreas Privadas Argentinas (LAPA) -en ese momento en manos de la Fuerza Aérea luego de la quiebra privada-, pero finalmente la operación no se concretó 43

Desde la creación de Socma en 1976 hasta 1981, el grupo llevó adelante numerosas inversiones para diversificarse por fuera del sector de la construcción, donde mantenía una presencia importante a través de su participación en Impresit Sideco. Sin embargo, la mayoría de las iniciativas no llegó a desarrollarse y el principal canal de expansión vendría a partir de su inserción en el sector automotriz.

Para el año 1981 la situación de Sevel estaba lejos de haberse estabilizado: la crisis económica recrudeció luego del fracaso de la gestión de Martínez de Hoz y la empresa experimentó una fuerte caída en su participación en las ventas (véase gráfica 5). La fusión entre Fiat y Peugeot todavía no había finalizado, pero, ante el agravamiento de la situación, la firma francesa decidió retirarse de la dirección compartida. A mediados de año, Fiat tomó el control de la empresa y nombró director general a Armando Amasanti, quien ya había estado a cargo de la reconversión de la firma de tractores. Mas allá del mal desempeño, los problemas generados por el descontrol inflacionario también fueron considerables en una organización como Fiat, especialmente en las funciones más básicas de la contabilidad de la empresa.

A Fiat le molestaba perder plata y no saber por qué. La inflación no bajaba del $10 \%$ mensual. Para los argentinos era parte de un panorama más o menos conocido. Pero era inmanejable para un ser humano normal. La moneda no se sabe cuál es. Sólo los argentinos podemos sobrevivir ahí [...]. Cuando vimos los libros contables nos dimos cuenta que estaban hechos siguiendo los criterios de la casa matriz, sistemas hechos en países con baja inflación. Si lo aplicabas en un país con una inflación de más del $100 \%$ te daba algo absurdo [...]. Estaban perdidos en un infierno 44

Ante ese panorama, una de las posibles salidas que se discutía en Fiat era dejar de invertir y retirarse del país, como había hecho General Motors poco tiempo antes 45 Sin embargo, ese antecedente también daba una referencia del costo económico que implicaría la decisión. La firma estadunidense había tenido que desembolsar cerca de 450000000 de dólares para indemnizar a concesionarios y proveedores. La opción alternativa, la que se adoptó finalmente, fue vender Sevel a un empresario local.

Según Francisco Macri, las conversaciones con Fiat se iniciaron en agosto de 1981, es decir, poco después de que la firma italiana retomara el control de Sevel, pero las negociaciones sobre las condiciones concretas del acuerdo se desarrollaron entre abril y junio de 1982, casi un año después ${ }^{46}$ Durante ese lapso, Fiat llevó adelante una fuerte reestructuración, para reducir la estructura de la empresa; en la primera fase se decidió eliminar las dos sedes centrales y concentrar

\footnotetext{
${ }^{43}$ Entrevista a ex directivos de Socma, abril y mayo de 2017.

${ }^{44}$ Entrevistado 2, abril de 2017.

${ }^{45}$ La posibilidad de una retirada de Argentina se manejó - no abiertamente- desde que Fiat tomó el control de la empresa: "La alternativa a la reestruturación que se estaba haciendo era cerrar. Cuando Fiat se hace cargo de Sevel eso se transformó en una posibilidad cierta. Vino un avión con una delegación de directivos italianos. Era evidente que se estaba evaluando el costo de cerrar, eso lo charlamos con Amasanti. Nosotros tratamos de dibujar el panorama de tal forma que la empresa se quedara”. Entrevistado 3, mayo de 2017, Buenos Aires.

${ }^{46}$ Revista Mercado, 15 de julio de 1982.
} 


\section{GRÁFICA 5. PARTICIPACIÓN RELATIVA EN EL MERCADO DE LAS PRINCIPALES GUATRO FIRMAS AUTOMOTRICES}

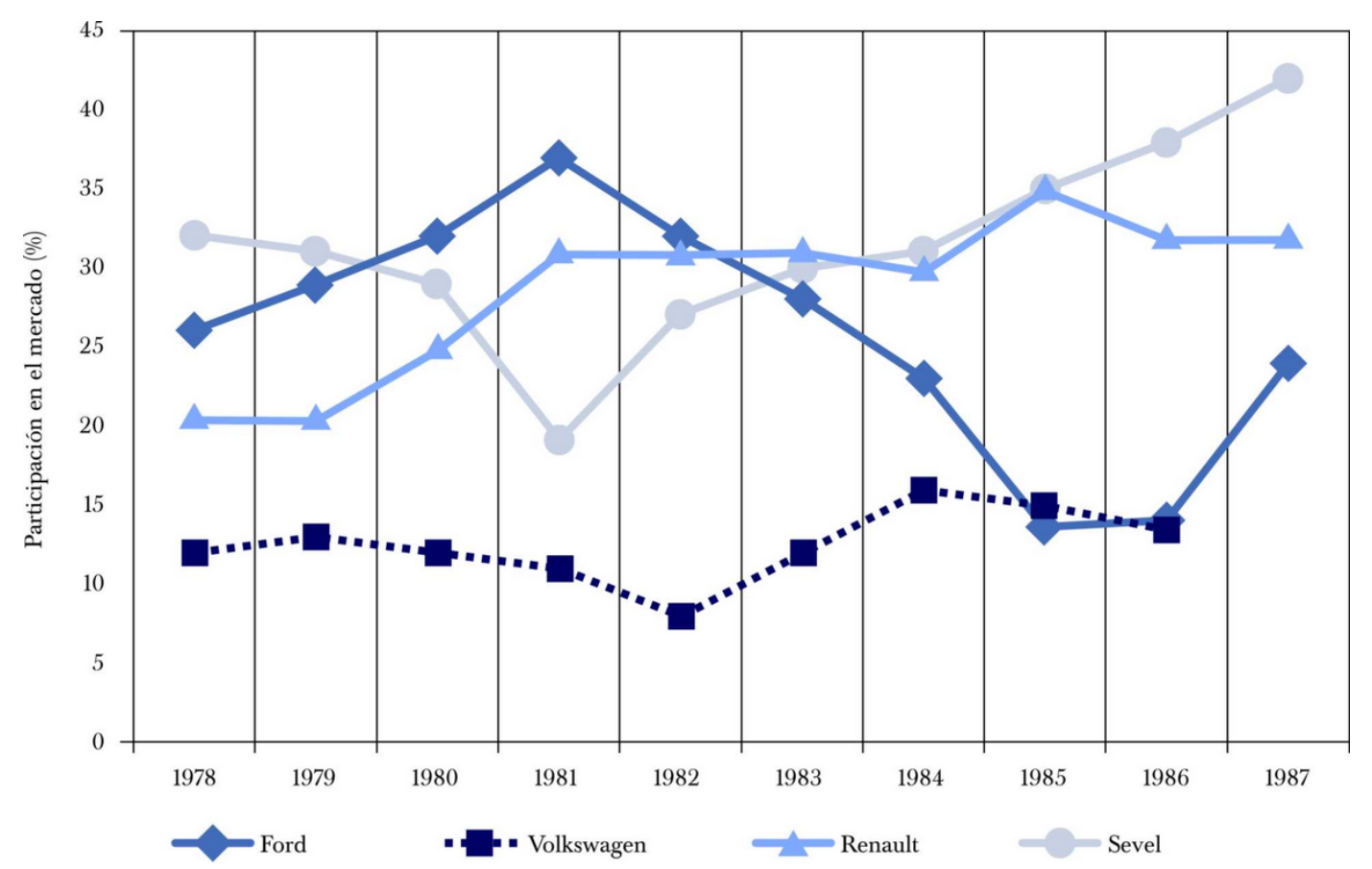

Nota: en 1987 se incluye en Ford la producción conjunta Ford-VW, correspondiente a Autolatina. Fuente: Maceira (1995) con base en Proyecto Sector Automotriz Terminal y Autopartista (1989).

la dirección general y todas las otras direcciones en la planta de El Palomar. Se transfirió el montaje de los productos Peugeot de Berazategui a El Palomar y la mecánica a Córdoba, operándose una profunda racionalización de los componentes estratégicos y de los modelos fabricados. Según Amasanti, "esto se llevó a cabo entre agosto y noviembre de 1981, logrando concentrar 80 \% de la reestructuración, que se completó en abril de 1982” (Fiat Auto Argentina, 2009, p. 165).

La última etapa de las negociaciones tuvo lugar entre abril y junio de 1982, casi en simultáneo con la guerra de las Malvinas ${ }^{47}$ Los entrevistados coinciden en que la crítica situación económica, sumada a la incertidumbre por el conflicto bélico, fueron puntos utilizados a su favor por los directivos del grupo que participaron en la negociación. El otro punto clave fue el antecedente de la retirada de General Motors.

\footnotetext{
${ }^{47}$ Pocos días después de cerrado el acuerdo, Fracisco Macri declaraba: "Hace más de veinte años [1962] que colaboro y participo en distintas actividades con el grupo Fiat [...]. Hace un año atrás, durante una de las etapas de reconversión del grupo, cuando Peugeot decidió alejarse del manejo de Sevel, Fiat pidió mi colaboración. Entendieron que mi conocimiento del mercado local podía ayudar al grupo, consolidándose en función del nuevo esquema económico [...]. En noviembre (1981) asumí la presidencia, y en junio de este año [1982] decidí convertirme en socio local [...]”. Revista Mercado, 15 de julio de 1982.
} 
Así los testimonios: "Franco sabía que el antecedente que existía era la retirada de General Motors, que había gastado millones de dólares indemnizando a los trabajadores y a las concesionarias. Entonces se hizo el cálculo de lo que les costaría a Fiat irse del país y se negoció con ese dato. Además, los italianos pensaban que la crisis económica se iba agudizar más. La compra fue una 'negoción'" 48

La negociación consistía en lo siguiente... en el quilombo (sic) que era la Argentina aún antes de Malvinas y con Malvinas ni hablar, Fiat quería irse del país, tenía su automotriz fundida como todos los que no pudieron entender o adaptarse a las políticas de Martínez de Hoz. Se querían ir, pero una automotriz no se puede ir sin más, dejando un tendal... se tiene que ir de forma prolija. General Motors se fue de la Argentina en el '79/'80, pagó 450 millones de dólares para indemnizar concesionarios, proveedores, etc. Se tuvo que ir así para no afectar la marca. Esa era nuestra referencia, de modo que pagar 250 era una bicoca para Fiat. 49

La operación terminó de cerrarse a fines de junio de 1982. Según lo publicado en los medios de comunicación a partir de las declaraciones de los involucrados, consistió en la transferencia de $85 \%$ de las acciones de Sevel a Socma, más la transferencia de la participación accionaria en ImpresitSideco, que a partir de ese momento pasaría a denominarse Sideco Americana. ${ }^{50}$ Uno de los puntos del acuerdo era el compromiso de Fiat de hacer un aporte financiero de 200000000 de dólares -destinados principalmente a la cancelación de deudas que Sevel mantenía con Fiat Italia-, y el compromiso de compra de una serie de bienes industriales, comerciales y administrativos por un valor de 84000000 de dólares ${ }^{51}$ Según lo trascendido, el pago por estos bienes coincidía con importantes vencimientos del pasivo externo que todavía tenía Sevel (alrededor de 160000000 de dólares) ${ }^{52}$ Sin embargo, prácticamente la totalidad de la deuda externa de Sevel contaba con seguros de cambio 53 lo cual implicaba una importante entrada de recursos por el hecho de recibir dólares en un contexto de gran inestabilidad cambiaria y pagar en pesos gracias al régimen que estableció el gobierno de facto para alivianar la deuda externa de los privados.

${ }^{48}$ Entrevistado 1, abril de 2017.

${ }^{49}$ Entrevistado 2, abril de 2017.

${ }^{50}$ Revista Mercado, 15 de julio de 1982; 20 de diciembre de 1984.

${ }^{51}$ Las fuentes disponibles no coinciden exactamente con las cifras del acuerdo. Según el entrevistado 2, el monto total del aporte de Fiat fue de 250000000 de dólares. De ese monto, la mayor parte estaba destinada a cancelar la deuda que Sevel mantenía con Fiat Italia por importación de insumos, otra porción para la capitalización necesaria para que la firma pudiera completar la reconversión, y una última parte para capitalizar Sideco. Por otro lado, Francisco Macri (1997) señala, sin demasiadas precisiones, que compró la empresa por 80000000 de dólares e Impresit Sideco por 30000 000, todo financiado por Fiat. Revista Mercado, 15 de julio de 1982.

${ }^{52} \mathrm{El}$ acuerdo incluía ciertas pautas sobre la transferencia de tecnología y la cantidad de modelos a lanzar. "La operación era muy particular, no es como cuando uno vende una casa. Pero fue una operación real, con puja de intereses reales y acuerdos de intereses reales [...]. Macri no podía definir solo si incorporar modelos Fiat o Peugeot en el futuro. Pero Fiat tampoco podía decidir solo. Era un acuerdo de socios. Se pautaban ciertos márgenes, no menos de un modelo cada tantos años, había condicionamientos. Por ejemplo, el acuerdo establecía que el puesto de gerente general de la empresa debía ser un hombre de la Fiat. Por eso Armando Amasanti se quedó un tiempo más”. Entrevistado 2, abril de 2017.

${ }^{53}$ A partir del agotamiento de la política sustentada en el "enfoque monetario de Balanza de Pagos", de la salida de Martínez de Hoz como ministro de Economía en febrero de 1981 y de una severa situación de escasez de divisas, en 1981 y 1982 se llevó a cabo una serie de fuertes devaluaciones para intentar superar el estrangulamiento externo. Las depreciaciones del peso provocaron un deterioro de la situación financiera de muchas grandes empresas que se habían endeudado en dólares en el exterior durante los años previos. En dicho marco, el Banco Central de la República 
La importancia de los beneficios de los seguros de cambio en el éxito de la operación fue reconocida por Francisco Macri años después:

Paulatinamente empezamos a sanear la empresa. De inmediato recuperamos para Sevel y para Fiat montos muy significativos de préstamos pendientes que Fiat había otorgado. También pudimos cancelar las deudas con el gobierno central. Domingo Cavallo, por ese entonces presidente del Banco Central, había nacionalizado las deudas del sector privado en 1982 y la medida tuvo un impacto positivo para Fiat y para Sevel (Macri, 1997, p. 159).

Como parte del acuerdo, Fiat se comprometió a adquirir para la exportación 25000 vehículos durante los primeros tres años, equivalentes a órdenes por 30000000 de dólares hasta 1985 . También existió el compromiso de la automotriz italiana de brindar apoyo técnico a cambio del pago de regalías y la continuidad de parte del management.

Como se mencionó, la operación no involucró sólo a Sevel, sino también a Impresit Sideco y a algunas inversiones conjuntas en el exterior. De hecho, el salvataje de la empresa constructora fue un factor muy importante para Francisco Macri.

Lo importante para mí es Impresit Sideco para entender toda la operación. Estaba fundida, no sé bien por qué. Había hecho mucha obra pública, autopistas, playas subterráneas, y demás. Y Macri era esencialmente un constructor, amaba Impresit, era su empresa [...]. A Macri le gustaban los negocios de entrar y salir, como la construcción, son uno o dos tres años y te fuiste. Por eso no le gustaba la industria. No tenía ningún negocio en la industria. No le gustaba hacer todos los días lo mismo [...]. Macri tenía fundido Impresit. Entonces Fiat dice, “yo te capitalizo Impresit-Sideco, te repongo el capital y te la doy toda a vos, recuerdo una cifra de 30 millones de dólares, cambia a Sideco Americana, a cambio de eso, vos te hacés cargo de Sevel, con el arte que vos tenés para manejar negocios en Argentina para que sobreviva la marca no tenga desprestigio" 54

El acuerdo se firmó a fines de junio de 1982 y marcó un punto de partida, tanto para Sevel como para el grupo Macri. Amasanti continuó en el puesto de director general hasta octubre de 1983 pero, por parte de Socma, Ricardo Zinn fue nombrado presidente de la compañía. En la práctica se dio una división de tareas mediante la cual Amasanti se encargaba, principalmente, de las tareas relacionadas con la producción y funcionamiento de las plantas, y Zinn de las funciones financieras y de representación. Macri se reservó para sí encargarse de la relación con Fiat Italia.

Durante la primera etapa de la nueva gestión el objetivo central consistió en mejorar los números de la empresa, continuando con la racionalización productiva 55 que estaba en marcha, así como terminar el saneamiento financiero. Luego, se inició una importante renovación en los modelos 56

Argentina estableció distintos regímenes de seguros de cambio que establecieron tasas de cambio preferenciales para que las firmas pagaran sus deudas con acreedores externos. Las devaluaciones sucesivas posteriores implicaron un inmenso subsidio al sector privado por parte del Estado argentino (Basualdo 2006; Schvarzer, 1986).

${ }^{54}$ Entrevistado 2 , abril de 2017.

${ }^{55}$ Sevel redujo 60 \% la nómina previa a la fusión de Fiat y Peugeot. En 1980 había 38851 empleados ocupados en forma directa en la industria y al finalizar 1990 apenas se registraban 17430 (Bil, 2017b, p. 306).

${ }^{56}$ Sevel terminó la producción del Peugeot 404 en 1980, Fiat 128 en 1981 y Fiat 600, 133 y 125 en 1982 y presentó el Peugeot 505 y el Fiat 147 en 1981, Europa y Super en 1982-1983, Regatta en 1985, Brío y Duna en 1987 y Uno en 1988, véase Bil (2017b, pp. 306-307). 
producidos, un reposicionamiento de la marca en el mercado y un fuerte incremento de las exportaciones de vehículos. En 1984 se produce otro hito cuando General Motors -que hacía cinco años había dejado de operar en el país- le otorga a Sevel la licencia para fabricar la Pick-up C10. Producto de estos cambios, y de una mejora en la situación macroeconómica, el desempeño de la empresa se recuperó notablemente a partir de 1983, tanto en las ventas como en la participación en el mercado local (véanse gráficas 3 y 5 ).

\section{Conclusiones}

La diversificación del grupo Macri y su inserción en la industria automotriz tiende a reforzar la importancia de un elemento presente en la bibliografía que analiza el crecimiento de los grupos empresarios en las décadas de 1970 y 1980: la capacidad de estas organizaciones para expandirse en momentos de crisis e incertidumbre económica y política. Sin embargo, en el caso estudiado aparece como central un elemento que sólo aparece en forma tangencial en la producción académica sobre el tema: la relación con el capital extranjero. En el caso de Socma, la adquisición de una de las principales firmas industriales del país fue posible gracias a la decisión de Fiat de retirarse de la producción de automóviles en Argentina.

La crisis mundial del sector automotriz, la reestructuración de Fiat a nivel global, la inestabilidad macroeconómica en Argentina, la caída del poder adquisitivo del salario en el país, y la apertura en el sector que instauró la última dictadura militar, llevó a la filial local a dar un giro en su estrategia empresarial. La multinacional italiana implementó una profunda reconversión, que incluyó la asociación con Peugeot, la descentralización organizativa, y la reducción de costos de producción. La decisión de transferir la firma a un empresario local fue la etapa final de este proceso de ajuste 57

El grupo Macri transitaba un camino inverso. Luego de su crecimiento en la obra pública durante la década anterior, había iniciado una imporante diversificación. Gran parte de las nuevas inversiones se habían orientado a aprovechar las oportunidades que ofrecía la política de privatización periférica del gobierno de facto. La decisión de Fiat de transferir el negocio automotriz a un empresario local para no pagar los costos asociados a una retirada total del país -como la efectuada por General Motors un tiempo antes-, le ofreció al grupo la oportunidad de comprar Sevel, pactando condiciones sumamente favorables, que serían definitorias en el éxito de la firma durante los años siguientes.

Este artículo busca ser el punto de partida para futuras indagaciones que analicen la aportación que tuvo para los grupos económicos argentinos su asociación con el capital extranjero durante la etapa sustitutiva y las oportunidades que les abrieron, a partir de la instauración de las políticas aperturistas a mediados de la década de 1970. Queda pendiente un estudio sobre el papel que tuvieron las redes sociales construidas por los empresarios locales con los directivos de las empresas extranjeras, un activo que resultaría central en su crecimiento durante las décadas de 1970 y 1980.

\footnotetext{
${ }^{57}$ Bil (2017b) muestra un camino similar para Renault, que luego de las dificultades durante la década de 1980, y, específicamente, luego de la crisis de 1989, la firma decide venderle su filial al grupo Antelo (que conformará Compañía Interamericana de Automóviles S. A. entre 1992 y 1997).
} 


\section{LISTA DE REFERENCIAS}

Acevedo, M., Basualdo, E. M. y Khavisse, M. (1990). ¿QQuién es quién? Los dueños del poder económico (Argentina, 1973-1987). Buenos Aires: Editora/Pensamiento Jurídico Editora.

Amico, F. (2011). Notas sobre la Industrialización por Sustitución de Importaciones en Argentina: Buscando adentro la fuente de la competitividad externa.H-industri@, 5(9), 267-269.

Argentina. Presidencia de la Nación (1979). Ley 21.932. Buenos Aires: Ministerio de Justicia y Derechos Humanos de la Nación.

Asociación de Fabricantes de Automotores (1990). Anuario Estadístico. Buenos Aires: Autor. Recuperado de http://www.adefa.org.ar/es/estadisticas-anuarios

Azpiazu, D. y Basualdo, E. M. (1989). Cara y contracara de los grupos económicos: Estado y promoción industrial en la Argentina. Buenos Aires: Cántaro Editores.

Baranson, J. (1971). La industria automotriz en los países en desarrollo. Madrid: Tecnos/Banco Mundial.

Barbero, M. I. y Lluch, A. (2016). Family capitalism in Argentina: Changes and continuity over the course of a century. En P. Fernández y A. Lluch (Eds.), Evolution of family business (pp. 123-154). Cheltenham: Edward Elgar Publishing.

Barbero, M. I. y Motta, J. (2007). Trayectoria de la industria automotriz en la Argentina desde sus inicios hasta fines de la década de 1990. En M. Delfini, D. Dubbini, M. Lugones y I. Rivero (Eds.), Innovación y empleo en tramas productivas de Argentina (pp. 189-229). Buenos Aires: Prometeo Libros.

Barjot, D. (2002). La percée internationale du génie civil italien: L'exemple d'Impresit (19291973). Outre-mers, 89(334), 251-277. Dor: 10.3406/outre.2002.3937

Barrera, M. A. (2012). El legado de la última dictadura en el mercado hidrocarburífero: La antesala de las reformas de los noventa. Realidad económicano, 267, 19-42.

Basualdo, E. M. (2006). Estudios de historia económica argentina: Desde mediados del siglo XX a la actualidad. Buenos Aires: Siglo Veintiuno Editores.

Bil, D. (2017a). La crisis mundial del sector automotriz (1978-1982) y los efectos sobre el complejo en Argentina. Projeto História: Revista do Programa de Estudos Pós-Graduados de História, 60, 281-318. DOI: $10.23925 / 2176-2767.2017 \mathrm{v} 60 \mathrm{p} 281-318$

Bil, D. (2017b). Trayectoria de una empresa multinacional en la crisis automotriz de los 80's: El caso de Renault Argentina. Anuario de la Escuela de Historia Virtual, 8(11), 92-116.

Carvalho, R. y Bernardes, R. (1998). Cambiando con la economía: La dinámica de empresas líderes en Brasil. En W. Peres (Ed.), Grandes empresas y grupos industriales latinoamericanos, expansión y desafíos en la era de la apertura y la globalización (pp. 151-218). México: Siglo Veintiuno.

Casalino, Ch. (2010). Italian big business and the Italian automotive industry. Fiat internationalization in the Vittorio Valletta Era and its ongoing reorganization (1946-1972). Jahrbuch für Wirtschaftsgeschichte/Economic History Yearbook, 51(1), 89-106. Dor: 10.1524/jbwg.2010.51.1 .89

Castellani, A. (2009). Estado, empresas y empresarios: La construcción de ámbitos privilegiados de acumulación entre 1966 y 1989. Buenos Aires: Prometeo Libros.

Castellani, A. y Serrani, E. (2010). La persistencia de los ámbitos privilegiados de acumulación en la economía argentina. El caso del mercado de hidrocarburos entre 1977 y 1999.H-industri@, $6(4), 1-31$. 
Castro, C. (2014). La gerencia como actividad emprendedora: La internacionalización de la empresa argentina Siderca (1960-1996). Apuntes: Revista de Ciencias Sociales, 41(75), 109-140. DOI: $10.21678 /$ apuntes.75.718

Cerruti, G. (2010). El pibe: Negocios, intrigas y secretos de Mauricio Macri, el hombre que quiere ser Presidente. Buenos Aires: Planeta.

Cipolla, F. H. (2014). El Torino: Historia de una proeza industrial, tecnológica y deportiva. Buenos Aires: Lenguaje Claro.

Cohen, R. B. (1981). La reorganización internacional de la producción en la industria automotriz. El Trimestre Económico, 48(2), 383-404.

Comisión Económica para América Latina y el Caribe (1987). Reestructuración de la industria automotriz mundial y perspectivas para América Latina. Santiago de Chile: Autor.

Donald, N. M. (1988). Henry J. Kaiser and the Establishment of an Automobile Industry in Argentina. Business History, 30(3), 329-345. DoI: 10.1080/00076798800000054

Fiat Auto Argentina (2009). Presencia italiana en el desarrollo cultural argentino: Homenaje de Fiat en sus 90 años. Buenos Aires: Autor.

Fitzsimons, A. y Guevara, S. (2018). La industria automotriz argentina y sus fuentes de ganancia: Un análisis de largo plazo (1960-2013). América Latina en la Historia Económica, 25(1), 239274. DOI: $10.18232 /$ alhe.859

Germano, L. (2007). Grande impresa e decisioni pubbliche. La Fiat da Campione nazionale atipico a "global player". Stato e Mercato, 80(2), 245-278.

Gooding, K. (1979b). The car majors embark on a revolutionary change of course. Financial Times, 12.

Green, R. H. y Laurent, C. (1988). El poder de Bunge y Born. Buenos Aires: Legasa.

Harari, I. (2009). La desnacionalización automotriz: Los casos de IAME e IKA. Realidad Económica, 244, 37-60.

Harari, I. y Bil, D. (2017). Desarrollo y crisis en una terminal automotriz: El caso de Industrias Kaiser Argentina (IKA), 1955-1967. Revista Digital de la Escuela de Historia, 9(21), 123-151.

Iramain, L. (2013). Los “ganadores” de un sector en crisis. El desempeño económico de las grandes empresas siderúrgicas, Argentina (1976-1981). H-industri@, 17(7), 1-28.

Katz, J. (2009). Innovación, tecnología y desarrollo en la economía argentina: Una visión histórica. En J. Katz (Ed.), Del Ford Taunus a la Soja Transgénica: Reflexiones en torno a la transición argentina al siglo XXI (cap. 1). Buenos Aires: Edhasa.

Katz, J. y Ablin, E. (1977). Tecnología y exportaciones industriales: Un analisis microeconomico de la experiencia argentina reciente. Desarrollo Económico, 17(65), 89-132. Dor: 10.2307/3466 702

Kosacoff, B., Vispo, A. y Todesca, J. (1991). La transformacion de la industria automotriz argentina: Su integracion con Brasil (Vol. 40). Buenos Aires: Comision Economica para America Latina y El Caribe.

Luedemann, M. S. (2003). Transformações na indústria automobilística mundial: $O$ caso do complexo automotivo no Brasil-1990-2002 (Tesis de doctorado). University of São Paulo, São Paulo.

Maceira, D. A. (1995). Reconversión industrial y cambio estratégico en el bloque automotriz argentino 1980-1993. Santiago: Comisión Económica para América Latina y el Caribe.

Macri, F. (1997). Macri por Macri. Buenos Aires: Editorial Emecé.

Miranda, A. V. (2007). La industria automotriz en México: Antecedentes, situación actual y perspectivas. Contaduría y Administración, 22 1, 209-246. 
Morero, H. A. (2013). El proceso de internacionalización de la trama automotriz argentina. $H$ industri@, 12(7), 1-36.

Nochteff, H. (1991). Reestructuración industrial en la Argentina: Regresión estructural e insuficiencias de los enfoques predominantes. Desarrollo Económico, 31(123), 339-358. Dor: 10.230 7/3466909

Nofal, M. B. (1989). Absentee entrepreneurship and the dynamics of the motor vehicle industry in Argentina. Nueva York: Praeger Publishers.

Panigo, D., Gárriz, A., Lavarello, P., Monzón, N., Mancini, M. y Langard, F. (2017). La industria autopartista argentina: Estudio de caso para el análisis de sus desafíos de inserción comercial. En D. Panigo, A. Gárriz, P. Lavarello y M. Schorr (Eds.), La encrucijada del autopartismo en América Latina (pp. 441-481). Buenos Aires: Asociación de Pensamiento Económico Latinoamericano.

Rougier, M. (2012). Estrategias empresariales en contextos de alta incertidumbre. Desafíos de una empresa productora de aluminio en la Argentina (1970-2001). Apuntes: Revista de Ciencias Sociales, 39(70), 239-272. DoI: 10.21678/apuntes.70.651

Schorr, M. (2012). La desindustrialización como eje del proyecto refundacional de la economía y la sociedad. Argentina, 1976-1983. América Latina en la Historia Económica, 19(3), 31-56. DOI: 10.18232 /alhe.v19i3.528

Schvarzer, J. (1983). Cambios en el liderazgo industrial argentino en el período de Martínez de Hoz. Desarrollo Económico, 23(91), 395-422. DoI: 10.2307/3466519

Schvarzer, J. (1986). La política económica de Martínez de Hoz. Buenos Aires: Hyspamerica.

Schvarzer, J. (1994). Grandes grupos económicos en la Argentina: Formas de propiedad y lógicas de expansión. Buenos Aires: Centro de Investigación de la Situación del Estado Administrativo.

Shaiken, H. (1995). Technology and work organization in Latin American motor vehicle industries. Santiago: Comisión Económica para América Latina y el Caribe.

Sourrouille, J. V. (1980). Transnacionales en América Latina: El complejo automotor en Argentina. México: Nueva Imagen/Instituto Latinoaméricano de Estudios Transnacionales.

Tarditi, R. J. (2000). La crisis mundial de los '70 y los '80 observada a partir de la producción automotriz. Buenos Aires: Programa de Investigación sobre el Movimiento de la Sociedad Argentina.

Teitel, S. y Thoumi, F. E. (1986). From import substitution to exports: The manufacturing exports experience of Argentina and Brazil. Economic Development and Cultural Change, 34(3), 455490. DOI: $10.1086 / 451545$

Volpato, G. (2001). Corporate governance at Fiat SpA. Corporate governance, innovation and economic performance in the EU (pp. 1-91) [Working Paper for EU Research Project]. Recuperado de www.insead.fr/cgep/Research/Industrystudies/Automobiles/Fiat.pdf 